\title{
Clinical epidemiology of premenstrual disorder: informing optimized patient outcomes
}

\author{
This article was published in the following Dove Press journal: \\ International Journal of Women's Health \\ 25 September 2015 \\ Number of times this article has been viewed
}

\author{
Lynne LL Robinson' \\ Khaled MK Ismail ${ }^{1,2}$ \\ 'Department of Obstetrics \\ and Gynaecology, Birmingham \\ Women's Hospital, Birmingham, UK; \\ 'Birmingham Centre for Women's \\ and Children's Health, School of \\ Clinical and Experimental Medicine, \\ College of Medical and Dental \\ Sciences, University of Birmingham, \\ Birmingham, UK
}

\begin{abstract}
Premenstrual disorders encompass a spectrum that ranges from mild cyclical psychological and somatic symptoms to the rarer but much-more-severe premenstrual dysphoric disorder. This condition is serious and the etiology is unclear, but possible causes include genetic factors, hormonal fluctuations, and neurotransmitter dysfunctions. Differentiation from other affective disorders can be difficult but is key to providing appropriate management. This comprehensive review will discuss the most-recent classification of premenstrual disorders, etiology, diagnosis, and potential current management strategies.
\end{abstract}

Keywords: premenstrual dysphoric disorder, progesterone, oestrogen, oophrectomy, GNRH analogues

\section{Introduction}

The syndrome of premenstrual tension was first described in the 1930s. ${ }^{1}$ Since then there have been various terminologies for a collection of psychological and physical symptoms, which occur in the luteal phase of the menstrual cycle and are relieved by menstruation. Approximately, $50 \%-80 \%$ of women will experience some premenstrual symptoms that may vary from mild to severe, ${ }^{2}$ but the prevalence of the severe form of psychological symptoms, known as premenstrual dysphoric disorder (PMDD), ranges from 3\%-9\%..$^{2-6}$ There have been various terminologies used to describe the syndrome over the years, which include premenstrual syndrome (PMS), premenstrual disorder (PMD), and late luteal-phase dysphoric disorder (American Psychiatric Association 1987), and finally PMDD (American Psychiatric Association 1994). To address the difficulty in diagnosis, the Consensus Group of the International Society for Premenstrual Disorders ${ }^{7}$ has published definitions and diagnostic criteria for a group of interlinked disorders that are now termed PMDs, and the previously known PMS is now termed core PMD (Table 1). ${ }^{8,9}$ The classification has several advantages compared to its predecessors, mainly because it accounts for different clinical scenarios without losing the essential criteria for diagnosis. Moreover, it is useful to tailor management based on the patient's clinical categorization.

The key component of the core PMD is ovulation, and the symptoms must appear during the luteal phase and resolve by the end of menstruation. There should be a symptom-free period of time in the follicular phase before the symptoms commence again. A critical factor is the impact the premenstrual symptoms have on the patients' lifestyle. The variations in core PMD symptoms are outlined in Table 1.

Symptoms associated with PMDs can vary from being somatic, psychological, or a mixture of both. ${ }^{11}$ PMDD represents a type of PMD in which the psychological symptoms are severe. In view of the implications of such a diagnosis on management strategies and the serious consequences of delayed diagnosis or substandard
Correspondence: Khaled MK Ismail Birmingham Women's Foundation Trust, Mindelsohn Way, Edgbaston, Birmingham BI 5 2TG, UK

Tel +0I2I 6272775

Email k.ismail@bham.ac.uk cc) (i) (5) 2015 Robinson and Ismail. This work is published by Dove Medical Press Limited, and licensed under Creative Commons Attribution - Non Commercial (unported, v3.0) LY LC License. The full terms of the License are available at http://creativecommons.org/licenses/by-nc/3.0/. Non-commercial uses of the work are permitted without any further how to request permission may be found at: http://www.dovepress.com/permissions.php 
Table I The classification of premenstrual disorders

\begin{tabular}{ll}
\hline Premenstrual disorder category & Characteristics \\
\hline Core premenstrual disorder & Symptoms occur in ovulatory cycles \\
& Symptoms are not specified - may be somatic and/or psychological \\
& Symptoms absent after menstruation and before ovulation \\
& Symptoms recur in luteal phase \\
& Symptoms must be prospectively rated (minimum of two cycles) \\
& Symptoms must cause significant disruption to lifestyle \\
& \\
Variants of PMD & Symptoms of an underlying psychological, somatic, or medical disorder significantly worsen \\
Premenstrual exacerbation & premenstrually \\
PMD due to nonovulatory ovarian & Symptoms result from ovarian activity other than those of ovulation \\
activity (rare) & Symptoms result from exogenous progestogen administration \\
Progestogen-induced PMD & Symptoms from continued ovarian activity although no menstruation due to \\
PMD with absent menstruation & suppression or surgery \\
\hline
\end{tabular}

Note: Adapted from Springer in Archives of Women's Mental Health. Volume I4(I). 20I I. Pages I3-2I. Towards a consensus on diagnostic criteria, measurement and trial design of the premenstrual disorders: the ISPMD Montreal consensus. O'Brien PM, Bäckström T, Brown C, et al; with kind permission from Springer Science and Business Media. ${ }^{10}$

Abbreviation: PMD, premenstrual disorder.

management, there are strict criteria for its diagnosis that aim to differentiate it from other types of core PMD. These criteria were set by the American Psychiatric Association Diagnostic and Statistical Manual of Mental Disorders, fourth Edition (DSM-IV) where the diagnosis requires five out of eleven specified symptoms (Table 2).

\section{Premenstrual disorders: etiology Hormones}

The etiology of PMD is unclear. There is some evidence for a genetic link, as demonstrated in a study comparing PMD in monozygotic and dizygotic twins. ${ }^{12}$ The most postulated theories for the culprits underlying PMD are estrogen and progesterone. It has been thought that estrogen or progesterone deficiency may exacerbate PMD symptoms. ${ }^{1}$ Indeed, treatment of PMD with progesterone suppositories was at one point a popular treatment. ${ }^{13}$ However, the converse is now considered to be the case, as evidence synthesized from randomized trials has not shown the efficacy of this treatment. ${ }^{14}$ Interestingly, core PMD symptoms are absent during pregnancy, a time when there are extremely high levels of endogenous progesterone and estrogen. It seems, however, unlikely that women affected by PMD have different levels of endogenous hormones than do unaffected women. In fact, measurement of progesterone levels has not shown any significant difference between women with core PMD versus control groups. ${ }^{15}$ They may, however, be more sensitive to fluctuations in these hormones levels. ${ }^{16-18}$ Women with PMD tend to develop negative mood and somatic symptoms with normal levels of endogenous hormones. It was reported that when pituitary downregulation is achieved and add-back hormone replacement given, PMS symptoms can be reintroduced. ${ }^{18}$ Nevertheless, the relationship between progesterone and PMS symptoms is not clear

Table 2 Summary of DSM-IV criteria for PMDD

\begin{tabular}{|c|c|}
\hline A. Symptoms must occur during the week before menses and remit a few days & I. Depressed mood or dysphoria \\
\hline after onset of menses & 2. Anxiety or tension \\
\hline \multirow[t]{9}{*}{ Five of the following symptoms and at least one must be (I), (2), (3), or (4) } & 3. Affective lability \\
\hline & 4. Irritability \\
\hline & 5. Decreased interest in usual activities \\
\hline & 6. Concentration difficulties \\
\hline & 7. Marked lack of energy \\
\hline & 8. Marked change in appetite, overeating, or food cravings \\
\hline & 9. Hypersomnia or insomnia \\
\hline & 10. Feeling overwhelmed \\
\hline & II. Other physical symptoms, ie, breast tenderness, bloating \\
\hline
\end{tabular}

B. Symptoms must interfere with work, school, usual activities, or relationships

C. Symptoms must not merely be an exacerbation of another disorder

D. Criteria A, B, and C must be confirmed by prospective daily ratings for at least two consecutive symptomatic menstrual cycles

Abbreviations: DSM-IV, American Psychiatric Association Diagnostic and Statistical Manual of Mental Disorders, fourth Edition; PMDD, premenstrual dysphoric disorder. 
cut, as there is a lack of reduction in somatic and psychological symptoms with the use of mifepristone, a progesterone antagonist. ${ }^{19}$ Hence, the interaction between progesterone and PMS symptoms is probably not mediated through the classic progesterone receptor, but the relationship with progesterone must be more complex.

Estrogen appears to have marked effects on central nervous system activity, and these appear mainly to be mood enhancing. It is thought to selectively increase cerebral blood flow, provide neuroprotection, and have differential effects on neurotransmitters. Estrogen acts as a cholinergic agonist in selective brain regions and decreases dopamine D2 receptor sensitivity and possibly other dopaminergic receptors.

The estrogen effects on endorphins vary, but it can increase overall endorphic activity. ${ }^{20}$ Its influence is not limited to monoamines, as it upregulates $\gamma$-aminobutyric acid (GABA), which is an important regulator of stress, anxiety, and alertness.

\section{Neurotransmitters and neurosteroids}

The neuroactive metabolites of progesterone are also known to affect mood and behavior, an effect that is mediated through GABA. These include 3-alpha-hydroxy-5-alphapregnane-20-one (allopregnanolone or ALLO) and 3-alphahydroxy-5-beta-pregnane-20-one (pregnanolone). These metabolites act as agonists of the GABA-A neurotransmitter. The neurosteroid ALLO is a GABA-A receptor-positive modulator and enhances the effect of GABA on the receptor. A deficiency of these metabolites has been associated with PMS-type symptoms, ${ }^{21}$ and acute treatment with substances such as ALLO has demonstrated anxiolytic effects. However, chronic exposure of progesterone metabolites to the GABA-A receptor can produce increased anxiety and depressive symptoms. ${ }^{22}$

Serotonin release is linked to variations in mood, libido, and appetite. A deficiency of serotonin can lead to depressive and anxiolytic like symptoms. Sex steroids have been postulated to modulate serotonin release, and estrogen enhances monoamine activity and increases serotonergic postsynaptic responsivity. Serotonin function is also altered in the luteal phase of the cycle, as demonstrated by decreased platelet uptake of serotonin ${ }^{23}$ and decreased baseline whole-blood serotonin. ${ }^{24}$

Estrogen appears to have a role in degradation of monoamine oxidase and catechol-o-methyl-transferase, resulting in an enhanced serotonin action and improved performance of selective serotonin reuptake inhibitors (SSRIs). Conversely, progesterone has the opposite effect of increasing monoamine oxidase and catechol-o-methyl-transferase activity, therefore decreases serotonin availability, which may result in depressive symptoms.

\section{Neuroreceptors}

Neuroimaging studies have demonstrated some differences in cerebral blood flow with ovarian suppression, which can be normalized with estrogen and progesterone replacement. ${ }^{25}$

Women with PMDD also show an increase in cerebellar activity from the follicular phase to the late luteal phase that correlates with worsening of mood. ${ }^{26}$ The cerebellum is rich in GABA-A receptors, and some animal studies suggest that women with PMD may have disordered regulation of GABA receptors. The increased cerebellar activity could reflect decreased GABA-mediated inhibition during the luteal phase of the cycle. There also appear to be increased cortical GABA concentrations in the luteal phase of women with PMDD when compared with healthy subjects, who show decreased cortical GABA. ${ }^{27}$ This abnormal GABA-A receptor functioning could imply there is increased resistance to GABA agonists, such as pregnane metabolites, which may mediate mood changes in the luteal phase.

Interestingly, some work has been done to investigate the provocation of negative emotion and how it is handled by women with PMDD. In one study, the neural response to negative emotion was measured using magnetic resonance imaging. ${ }^{28}$ Researchers found that women with PMDD were less able than controls to inhibit incorrect responses to affectively negative words. Also, PMDD sufferers appeared to have less impulse control than did control subjects, due to modulation of the limbic system. ${ }^{28}$

These findings suggest that neurocircuitry in PMDD sufferers may be affected by hormonal fluctuations and disordered control of GABA receptors, and also that these patients may have a very different response to processing negative thoughts than do controls.

\section{Opioids}

Endogenous opioids include endorphins, enkephalins, and dynorphins. Various opioids bind selectively to different opioid receptors in the brain, producing specific effects on mood. In particular, high levels of $\beta$ endorphins have been identified in the portal system of the hypothalamus, and it is thought that they probably decrease pituitary secretion of gonadotrophins by exerting an effect on hypothalamic gonadotropin-releasing hormone $(\mathrm{GnRH})$ secretion.

$\beta$ endorphin levels have been demonstrated to be lower in the luteal phase of the cycle in women suffering from 
PMS. ${ }^{29,30}$ In addition, women suffering from PMS appear to have a blunted enhancement in the level of $\beta$ endorphins midcycle compared to control women. This low level of endorphins is linked with lethargy, low mood, and emotional instability, all of which are symptoms typical of PMS sufferers.

\section{Diagnosis of PMD}

The Consensus Group of the International Society for Premenstrual Disorders has categorized PMD into "core" and "variant" types. ${ }^{10}$ The pathophysiology behind PMD is linked with the presence of ovulation, as mentioned earlier. The exact mechanism for PMD is unclear, but the symptoms appear to be caused by the luteal phase of the menstrual cycle and therefore are most likely progesterone related. PMD like symptoms can also be caused by the use of exogenous progestogens. The key features are somatic and psychological symptoms, which occur exclusively within the luteal phase of the menstrual cycle and are relieved by menstruation. There must be a window of time between the end of ovulation and menstruation that is symptom free. These symptoms do not have to occur in every cycle but should occur in at least two out of three cycles. The impact these symptoms have on the patient's quality of life is key to the diagnosis and management of the patient.

Prospective symptom rating over several cycles is the gold standard for diagnosis; however, if this is not feasible, at least a symptomatology chart should be completed to accurately aid the diagnosis and exclude other pathologies such as affective disorders (Table 3 ). If the premenstrual symptoms are due to exacerbation of an underlying disorder, then the existing disorder should be managed appropriately or ovarian suppression should be used.

The diagnosis of PMD without menstruation involves identifying when ovulation occurs. This can be identified using ovulation kits or progesterone measurements, and the timing of ovulation is then related to the peak symptoms.

\section{Management}

PMD appears to be inextricably linked with fluctuations in hormone levels and in particular with progesterone. Therefore, one of the most common approaches to treating PMD

Table 3 The premenstrual symptoms screening tool

\begin{tabular}{|c|c|c|c|c|}
\hline Symptom & Not at all & Mild & Moderate & Severe \\
\hline \multicolumn{5}{|l|}{ I. Anger/irritability } \\
\hline \multicolumn{5}{|l|}{ 2. Anxiety/tension } \\
\hline \multicolumn{5}{|l|}{ 3. Tearful/increased sensitivity to rejection } \\
\hline \multicolumn{5}{|l|}{ 4. Depressed mood/hopelessness } \\
\hline \multicolumn{5}{|l|}{ 5. Decreased interest in work activities } \\
\hline \multicolumn{5}{|l|}{ 6. Decreased interest in home activities } \\
\hline \multicolumn{5}{|l|}{ 7. Decreased interest in social activities } \\
\hline \multicolumn{5}{|l|}{ 8. Difficulty concentrating } \\
\hline \multicolumn{5}{|l|}{ 9. Fatigue/lack of energy } \\
\hline \multicolumn{5}{|l|}{ 10. Overeating/food cravings } \\
\hline \multicolumn{5}{|l|}{ II. Insomnia } \\
\hline \multicolumn{5}{|l|}{ 12. Hypersomnia (needing more sleep) } \\
\hline \multicolumn{5}{|l|}{ 13. Feeling overwhelmed or out of control } \\
\hline \multicolumn{5}{|c|}{ 14. Physical symptoms: breast tenderness, headaches, joint/muscle pain, bloating, weight gain } \\
\hline \multicolumn{5}{|l|}{ Have your symptoms, as listed above, interfered with: } \\
\hline \multicolumn{5}{|l|}{ A. Your work efficiency or productivity } \\
\hline \multicolumn{5}{|l|}{ B. Your relationships with coworkers } \\
\hline \multicolumn{5}{|l|}{ C. Your relationships with your family } \\
\hline \multicolumn{5}{|l|}{ D. Your social life activities } \\
\hline \multicolumn{5}{|l|}{ E. Your home responsibilities } \\
\hline \multicolumn{5}{|l|}{ Scoring } \\
\hline \multicolumn{5}{|l|}{ The following criteria must be present for a diagnosis of PMDD: } \\
\hline \multicolumn{5}{|l|}{ I) At least one of I, 2, 3, or 4 is severe } \\
\hline \multicolumn{5}{|l|}{ 2) In addition, at least 4 of $\mathrm{I}-\mathrm{I} 4$ are moderate to severe } \\
\hline \multicolumn{5}{|l|}{ 3) At least one of $A, B, C, D, E$ is severe } \\
\hline \multicolumn{5}{|c|}{ The following must be present for a diagnosis of moderate to severe PMDD: } \\
\hline \multicolumn{5}{|l|}{ I) At least one of I, 2, 3, or 4 is moderate to severe } \\
\hline \multicolumn{5}{|l|}{ 2) In addition, at least 4 of $\mathrm{I}-14$ are moderate to severe } \\
\hline 3) At least one of $A, B, C, D, E$ is moderate to severe & & & & \\
\hline
\end{tabular}

Note: Adapted from Springer in Archives of Women's Mental Health. Volume 6(3). 2003. Pages 203-209. The premenstrual symptoms screening tool (PSST) for clinicians. Steiner M, Macdougall M, Brown E; with kind permission from Springer Science and Business Media. ${ }^{31}$

Abbreviation: PMDD, premenstrual dysphoric disorder. 
is to try ovulation suppression. The various methods of doing this are: combined oral contraceptive pill (COCP), GnRH analogues, and bilateral oophorectomy. Other approaches include antidepressants and the use of vitamin and mineral supplements and alternative therapies.

\section{Combined oral contraceptive pill}

The COCP has not shown dramatic results in randomized clinical trials with regard to its effect on PMD symptoms. This may be due to the action of progesterone within the preparation and also fluctuations in hormone levels inflicted by a 21/7 day regime. In randomized studies, monophasic and triphasic COCPs seem to improve mood and physical symptoms, but the monophasics have a marginally more-beneficial effect than triphasic pills, presumably due to the reduction in hormone fluctuations. ${ }^{32}$ However, as there was no placebo-controlled group, a placebo effect could not be excluded.

It is best to avoid COCPs containing 19-nortestosteronederived progestogens, as these can contribute to symptoms such as water retention, bloating, weight gain, and breast tenderness. A shorter pill-free window (24/4 days), lower doses of estrogen and progestogens, such as drosperinone, which has antimineralocorticoid and antiandrogenic properties, may be better options for women with PMDD and may improve symptom control. ${ }^{33,34}$ However, the effects of contraceptives containing drosperinone on PMDD symptoms have not been evaluated over more than three cycles. ${ }^{35}$

\section{GnRH analogues}

$\mathrm{GnRH}$ analogues initially increase the release of folliclestimulating hormone and luteinizing hormone from the anterior pituitary gland but then rapidly downregulate their release, causing pituitary suppression and anovulation. For most women with true PMDD or PMS, this suppression should relieve symptoms and act as a very effective test to differentiate between women with PMDD and a primarily affective disorder. However, long-term suppression of ovarian function leads to menopausal symptoms and more seriously to osteoporosis and cardiovascular disease. Therefore, add-back hormone replacement therapy (HRT) is required and estrogen-only HRT can be given with good effect without necessarily introducing PMS symptoms. Nonetheless, unopposed estrogen carries the risk of endometrial hyperplasia and carcinoma, and therefore progesterone must be added for endometrial protection. It is the progesterone component of add-back HRT that can be most troublesome with regard to PMS symptoms, and preferable options to limit this would include the Mirena intrauterine system (IUS) or tibolone, a synthetic anabolic steroid. A meta-analysis has shown that tibolone is less likely than conventional estrogen and progesterone to reintroduce PMS symptoms. ${ }^{36}$

\section{Progestogens}

Traditionally, progestogens have been used to treat PMS symptoms as it was thought that the condition was caused by progesterone deficiency. However, treatment has been found to be ineffective and can actually make symptoms worse or reinstate symptoms after ovarian suppression. ${ }^{37}$ This is due to the fact that progesterone metabolites can act via the GABA-A receptor.

Therefore, currently progesterone is not recommended as a treatment for PMD and should be avoided where possible and if required options such as drosperinone or the Mirena ${ }^{\circledR}$ IUS should be considered..$^{35}$

The Mirena ${ }^{\circledR}$ IUS may be used as a treatment for PMS symptoms on its own, but is only useful for this if it suppresses ovulation, which only occurs in $30 \%-40 \%$ of users. Patients may find that some PMS symptoms recur within the first few months after insertion of the Mirena ${ }^{\circledR}$ IUS, but this should improve with time as systemic absorption of the levonogestrel decreases.

\section{Estradiol}

Estradiol can be used in high doses (eg, $200 \mu \mathrm{g}$ patch) to suppress ovulation and therefore is effective in preventing PMD. ${ }^{38}$ Studies have shown that transdermal estrogens seem to be more effective and preferable because of the avoidance of first-pass metabolism and production of hepatic coagulation factors. In addition, oral estrogens cause more fluctuations in hormone levels, and higher doses of estrogen are required to achieve an effect. They also have a less-desirable biological effect by increasing levels of angiotensinogen, cortisol-binding globulin, thyroxine-binding globulin, sexhormone-binding globulin, and triglyceride levels. The estrone-to-estradiol ratio is also increased, and this is especially notable with conjugated equine estrogens.

Studies on mood in postmenopausal women show good

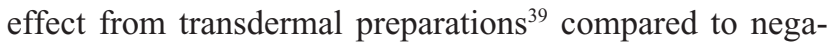
tive findings with oral preparations of conjugated equine estrogens, ${ }^{40}$ but there are no studies on women with PMD and oral estrogen. Transdermal estrogen can be administered in the form of a high-dose patch $(100-200 \mu \mathrm{g}),{ }^{41}$ gel, or implant. Patches and implants have been demonstrated to be superior to placebo and although studies have not been carried out on gels, they are often used and are likely to be as effective as patches and are often less irritating to the skin. Estrogen 
gel should be used in doses of 1-3 g per day (equivalent to a $200 \mu \mathrm{g}$ patch twice weekly).

Implants have been shown to be very effective but are less useful in younger women of reproductive age due to the need for endometrial protection with progesterone for up to 2 years after discontinuation of the implant. Unopposed estrogen carries the risk of endometrial hyperplasia, and therefore progesterone must be added to protect the endometrium. As mentioned previously, the most effective way of doing this without reintroducing symptoms would be to insert a Mirena ${ }^{\circledR}$ IUS. The Mirena can cause systemic progestogenic symptoms, but these are mostly transient and resolve within a few months of use. Alternatively, oral progesterone can be used in a low-dose short course such as norethisterone $2.5 \mathrm{mg}$ daily or utrogestan $200 \mathrm{mg}$ daily for 7 days per month.

Although these high doses of estrogen almost certainly suppress ovulation, women must be informed that these regimens are not contraceptive (unless Mirena ${ }^{\circledR}$ IUS is used) and additional precautions must be used.

A novel method of avoiding the progestogen-induced symptoms may be the advent of a new combination product, which combines a conjugated estrogen with the selective estrogen receptor modulator bazedoxifene. This product may prove useful in women with progestogen intolerance, as it avoids the addition of progesterone whilst providing endometrial protection. ${ }^{42}$ However, this product is not yet available in the UK.

\section{Selective serotonin reuptake inhibitors}

SSRIs are commonly used as a treatment for PMD. ALLO is a neuroactive steroid derived from progesterone that modulates the GABA receptor, and SSRIs may augment the action of ALLO or possibly work by increasing serotonergic activity. Meta-analyses have shown up to $60 \%$ improvement in symptom relief with the use of SSRIs and serotonin-norepinephrine reuptake inhibitors. ${ }^{43-45}$ The most useful drugs appear to be fluoxetine, sertraline, paroxetine, and escitalopram, ${ }^{46,47}$ along with the serotonin-norepinephrine reuptake inhibitor venlafaxine, and these are effective either used continuously or only in the luteal phase of the cycle. ${ }^{48}$ Other anxiolytics and antidepressants that act only on augmenting noradrenergic activity do not appear to significantly improve symptoms associated with PMD. ${ }^{49-51}$ SSRIs act better on affective rather than somatic symptoms and therefore may be preferable if mood symptoms are dominant.

The overall response to SSRIs in clinical trials ranges from $50 \%-90 \%$. There are some side effects, which are commonly nausea, insomnia, fatigue, headache, bowel upset, and decreased libido. These are usually transient but if troublesome, as sexual function returns rapidly on discontinuation of the treatment, then luteal-phase treatment may be preferable for those patients as they will only have side effects for 2 weeks of the cycle. If luteal-phase treatment is to be used, the SSRI is commenced 14 days before the expected onset of menstruation and stopped on day 1 of the cycle.

Other antidepressants such as tricyclics do not seem to have the same beneficial effect on PMS sufferers as SSRIs do and have been shown to be no better than placebo. ${ }^{50,51}$ This is likely due to the fact that PMS is associated with serotonergic activity.

\section{Bilateral oophorectomy}

Laparoscopic bilateral salpingo-oophorectomy is an extreme measure to treat PMD, but it is effective and is used in severe cases. ${ }^{52}$ The cessation of ovulation provides relief of symptoms, but first a trial of a GnRH analogue is advisable to help assess if the patient is suffering from true PMD or from an affective disorder. Once the diagnosis is made, caution has to be given to the age of the patient, as fertility will be removed and HRT will be required until at least the age of 50 years. Consideration should be given to performing a hysterectomy at the same time, as this would allow for estrogen-only HRT. The addition of progesterone to HRT to protect the endometrium can reintroduce symptoms, and if the uterus is to be retained, the Mirena ${ }^{\circledR}$ IUS is the preferable choice for endometrial protection. However, levonogestrel from the IUS can be absorbed, also leading to side effects, therefore a hysterectomy is likely to lead to a better outcome longterm unless there are excessive individual surgical risks. The other advantage of removing the uterus at the time of bilateral salpingo-oophorectomy is that there is some evidence to suggest that estrogen-only HRT confers a lower risk of breast cancer than combined HRT in postmenopausal women, which has implications for women later in life. ${ }^{53}$

\section{Alternative therapies}

Calcium has been used as a therapy for PMS. Estrogen plays a role in calcium metabolism regulation and vitamin $\mathrm{D}$ metabolism. Calcium levels therefore fluctuate throughout the menstrual cycle, and women who are hypocalcemic may be more likely to have an affective disorder such as PMD.

There is only weak evidence that vitamin B6 may have any benefit over placebo. ${ }^{54,55}$ Caution should be employed regarding increasing the dose of vitamin B6 if there is little or no effect, as there is a risk of peripheral neuropathy. The treatment should certainly be discontinued if there are any 
symptoms of numbness or tingling in hands or feet. Other treatments that have been used are magnesium, vitamin $\mathrm{E}$, soy isoflavones, and evening primrose oil, but there is limited evidence for any of these. ${ }^{55}$

The strongest evidence for alternative therapies lies with calcium, chasteberry, and cognitive-behavioral therapy. ${ }^{55-58}$

\section{Summary}

PMD can be a very distressing disorder and its variants also cause a great deal of disruption to quality of life. The pathogenesis involves ovulation, and for diagnosis the history must include either physical or psychological symptoms that occur in the luteal phase of the cycle and must be relieved during menstruation. A symptomatology chart covering at least 2 months should be used to aid an accurate diagnosis. If there is no symptom-free week following menstruation, then a psychiatric or physical condition is more likely and an alternative management strategy is required. If the PMS symptoms are mild and not disruptive to the patient's quality of life, then all that is required is reassurance and support.

Once a diagnosis of a core PMD is made, the main mode of treatment is to prevent ovulation. This decision is made in conjunction with patients' fertility and contraceptive needs. Inhibition of ovulation can be achieved using the COCP, estradiol, or GnRH analogues, and in some cases the Mirena ${ }^{\circledR}$ IUS may be helpful. Other approaches involve enhancing serotonin activity using SSRIs or alternative therapies, which may have limited benefit. The condition can be so disruptive and severe that bilateral salpingo-oophorectomy is required, but the HRT that is then necessary can cause symptoms to resume if it contains progesterone. For this reason hysterectomy is often considered as it allows for estrogen-only HRT. Surgery is a last resort and should only be considered after extensive counseling, and there must be a trial period with $\mathrm{GnRH}$ analogues before the decision is made.

\section{Disclosure}

The authors report no conflicts of interest in this work.

\section{References}

1. Frank RT. The hormonal causes of premenstrual tension. Arch Neur Psych. 1931;26(5):1053-1057.

2. Woods NF, Most A, Dery GK. Prevalene of perimenstrual symptoms. Am J Public Health. 1982;72(11):1257-1264.

3. Rivera-Tovar AD, Frank E. Late luteal phase dysphoric disorder in young women. Am J Psychiatry. 1990;147(12):1634-1636.

4. Johnson SR. The epidemiology and social impact of premenstrual symptoms. Clin Obstet Gynecol. 1987;30(2):367-376.

5. Merikangas KR, Foeldenyi M, Angst J. The Zurich Study. XIX. Patterns of menstrual disturbances in the community: results of the Zurich Cohort Study. Eur Arch Psychiatry Clin Neurosci. 1993;243(1):23-32.
6. Ramcharan S, Love EJ, Fick GH, Goldfien A. The epidemiology of premenstrual symptoms in a population-based sample of 2,650 urban women: attributable risk and risk factors. J Clin Epidemiol. 1992; 45(4):377-392.

7. Nevatte T, O’Brien PM, Bäckström T, et al; Consensus Group of the International Society for Premenstrual Disorders. ISPMD consensus on the management of premenstrual disorders. Arch Womens Ment Health . 2013;16(4):279-291.

8. Steiner M, Streiner DL, Steinberg S, et al. The measurement of premenstrual mood symptoms. J Affect Disord. 1999;53(3):269-273.

9. Halbreich U. The diagnosis of premenstrual syndromes and premenstrual dysphoric disorder - clinical procedures and research perspectives. Gynecol Endocrinol. 2004;19(6):320-334.

10. O’Brien PM, Bäckström T, Brown C, et al. Towards a consensus on diagnostic criteria, measurement and trial design of the premenstrual disorders: the ISPMD Montreal consensus. Arch Womens Ment Health. 2011; 14(1):13-21.

11. Ismail KM, Nevatte $\mathrm{T}, \mathrm{O}$ 'Brien $\mathrm{S}$, et al. Clinical subtypes of core premenstrual disorders: a Delphi survey. Arch Womens Ment Health. 2013;16(3):197-201.

12. Jahanfar S, Lye MS, Krishnarajah IS. The heritability of premenstrual syndrome. Twin Res Hum Genet. 2011;14(5):433-436.

13. Dalton K. The influence of menstruation on health and disease. Proc R Soc Med. 1964;57:262-264.

14. Sampson GA. Premenstrual syndrome: a double-blind controlled trial of progesterone and placebo. Br J Psychiatry. 1979;135:209-215.

15. Bäckström T, Sanders D, Leask R, Davidson D, Warner P, Bancroft J. Mood, sexuality, hormones, and the menstrual cycle. II. Hormone levels and their relationship to the premenstrual syndrome. Psychosom Med. 1983;45(6):503-507.

16. Halbreich U, Endicott J, Goldstein S, Nee J. Premenstrual changes and changes in gonadal hormones. Acta Psychiatr Scand. 1986; 74(6):576-586.

17. Halbreich U, Alt IH, Paul L. Premenstrual changes. Impaired hormonal homeostasis. Neurol Clin. 1988;6(1):173-194.

18. Schmidt PJ, Nieman LK, Danaceau MA, Adams LF, Rubinow DR. Differential behavioral effects of gonadal steroids in women with and in those without premenstrual syndrome. N Engl J Med. 1998; 338(4):209-216.

19. Chan AF, Mortola JF, Wood SH, Yen SS. Persistence of premenstrual syndrome during low-dose administration of the progesterone antagonist RU 486. Obstet Gynecol. 1994;84(6):1001-1005.

20. McEwen BS, Alves SE, Bulloch K, Weiland NG. Ovarian steroids and the brain: implications for cognition and aging. Neurology. 1997;48 (5 Suppl 7):S8-S15.

21. Rapkin AJ, Morgan M, Goldman L, Brann DW, Simone D, Mahesh VB. Progesterone metabolite allopregnanolone in women with premenstrual syndrome. Obstet Gynecol. 1997;90(5):709-714.

22. Smith SS, Gong QH, Li X, et al. Withdrawal from 3alpha-OH-5alphapregnan-20-One using a pseudopregnancy model alters the kinetics of hippocampal GABAA-gated current and increases the GABAA receptor alpha4 subunit in association with increased anxiety. $J$ Neurosci. 1998;18(14):5275-5284.

23. Ashby CR, Carr LA, Cook CL, Steptoe MM, Franks DD. Alteration of platelet serotonergic mechanisms and monoamine oxidase activity in premenstrual syndrome. Biol Psychiatry. 1988;24(2):225-233.

24. Rapkin AJ, Edelmuth E, Chang LC, Reading AE, McGuire MT, Su TP. Whole-blood serotonin in premenstrual syndrome. Obstet Gynecol. 1987; 70(4):533-537.

25. Berman KF, Schmidt PJ, Rubinow DR, et al. Modulation of cognitionspecific cortical activity by gonadal steroids: a positron-emission tomography study in women. Proc Natl Acad Sci U S A. 1997;94(16): 8836-8841.

26. Rapkin AJ, Berman SM, Mandelkern MA, Silverman DH, Morgan M, London ED. Neuroimaging evidence of cerebellar involvement in premenstrual dysphoric disorder. Biol Psychiatry. 2011;69(4): 374-380. 
27. Epperson CN, Haga K, Mason GF, et al. Cortical gamma-aminobutyric acid levels across the menstrual cycle in healthy women and those with premenstrual dysphoric disorder: a proton magnetic resonance spectroscopy study. Arch Gen Psychiatry. 2002;59(9):851-858.

28. Protopopescu X, Tuescher O, Pan H, et al. Toward a functional neuroanatomy of premenstrual dysphoric disorder. J Affect Disord. 2008; 108(1-2):87-94.

29. Chuong CJ, Coulam CB, Kao PC, Bergstralh EJ, Go VL. Neuropeptide levels in premenstrual syndrome. Fertil Steril. 1985;44(6):760-765.

30. Reid RL, Yen SS. Premenstrual syndrome. Am J Obstet Gynecol. 1981; 139(1):85-104.

31. Steiner M, Macdougall M, Brown E. The premenstrual symptoms screening tool (PSST) for clinicians. Arch Womens Ment Health. 2003;6(3):203-209.

32. Bäckström T, Hansson-Malmström Y, Lindhe BA, Cavalli-Björkman B, Nordenström S. Oral contraceptives in premenstrual syndrome: a randomized comparison of triphasic and monophasic preparations. Contraception. 1992;46(3):253-268.

33. Pearlstein TB, Bachmann GA, Zacur HA, Yonkers KA. Treatment of premenstrual dysphoric disorder with a new drospirenone-containing oral contraceptive formulation. Contraception. 2005;72(6):414-421.

34. Yonkers KA, Brown C, Pearlstein TB, Foegh M, Sampson-Landers C, Rapkin A. Efficacy of a new low-dose oral contraceptive with drospirenone in premenstrual dysphoric disorder. Obstet Gynecol. 2005; 106(3):492-501.

35. Lopez LM, Kaptein AA, Helmerhorst FM. Oral contraceptives containing drospirenone for premenstrual syndrome. Cochrane Database Syst Rev. 2009CD006586.

36. Wyatt KM, Dimmock PW, Ismail KM, Jones PW, O'Brien PM. The effectiveness of GnRHa with and without 'add-back' therapy in treating premenstrual syndrome: a meta analysis. BJOG. 2004;111(6): 585-593.

37. Ford O, Lethaby A, Roberts H, Mol BW. Progesterone for premenstrual syndrome. Cochrane Database Syst Rev. 2012;3:CD003415.

38. Watson NR, Studd JW, Savvas M, Garnett T, Baber RJ. Treatment of severe premenstrual syndrome with oestradiol patches and cyclical oral norethisterone. Lancet. 1989;2(8665):730-732.

39. Schmidt PJ, Nieman L, Danaceau MA, et al. Estrogen replacement in perimenopause-related depression: a preliminary report. Am J Obstet Gynecol. 2000;183(2):414-420.

40. Soares CN, Almeida OP, Joffe H, Cohen LS. Efficacy of estradiol for the treatment of depressive disorders in perimenopausal women: a double-blind, randomized, placebo-controlled trial. Arch Gen Psychiatry. 2001;58(6):529-534.

41. Smith RN, Studd JW, Zamblera D, Holland EF. A randomised comparison over 8 months of 100 micrograms and 200 micrograms twice weekly doses of transdermal oestradiol in the treatment of severe premenstrual syndrome. Br J Obstet Gynaecol. 1995;102(6):475-484.

42. Tella SH, Gallagher JC. Bazedoxifene + conjugated estrogens in HT for the prevention of osteoporosis and treatment of vasomotor symptoms associated with the menopause. Expert Opin Pharmacother. 2013; 14(17):2407-2420.

43. Rapkin AJ, Winer SA. The pharmacologic management of premenstrual dysphoric disorder. Expert Opin Pharmacother. 2008;9(3): $429-445$.
44. Dimmock PW, Wyatt KM, Jones PW, O’Brien PM. Efficacy of selective serotonin-reuptake inhibitors in premenstrual syndrome: a systematic review. Lancet. 2000;356(9236):1131-1136.

45. Marjoribanks J, Brown J, O’Brien PM, Wyatt K. Selective serotonin reuptake inhibitors for premenstrual syndrome. Cochrane Database Syst Rev. 2013;6:CD001396.

46. Yonkers KA, O’Brien PM, Eriksson E. Premenstrual syndrome. Lancet. 2008;371(9619):1200-1210.

47. Freeman EW, Sammel MD, Lin H, Rickels K, Sondheimer SJ. Clinical subtypes of premenstrual syndrome and responses to sertraline treatment. Obstet Gynecol. 2011;118(6):1293-1300.

48. Pearlstein TB, Halbreich U, Batzar ED, et al. Psychosocial functioning in women with premenstrual dysphoric disorder before and after treatment with sertraline or placebo. J Clin Psychiatry. 2000;61(2): 101-109.

49. Freeman EW, Rickels K, Sondheimer SJ, Wittmaack FM. Sertraline versus desipramine in the treatment of premenstrual syndrome: an open-label trial. J Clin Psychiatry. 1996;57(1):7-11.

50. Pearlstein TB, Stone AB, Lund SA, Scheft H, Zlotnick C, Brown WA. Comparison of fluoxetine, bupropion, and placebo in the treatment of premenstrual dysphoric disorder. J Clin Psychopharmacol. 1997; 17(4):261-266.

51. Eriksson E, Hedberg MA, Andersch B, Sundblad C. The serotonin reuptake inhibitor paroxetin is superior to the noradrenaline reuptake inhibitor maprotiline in the treatment of premenstrual syndrome. Neuropsychopharmacology. 1995;12(2):167-176.

52. Cronje WH, Vashisht A, Studd JW. Hysterectomy and bilateral oophorectomy for severe premenstrual syndrome. Hum Reprod. 2004;19(9):2152-2155.

53. Rossouw JE, Anderson GL, Prentice RL, et al; Writing Group for the Women's Health Initiative Investigators. Risks and benefits of estrogen plus progestin in healthy postmenopausal women: principal results From the Women's Health Initiative randomized controlled trial. JAMA. 2002;288(3):321-333.

54. Wyatt KM, Dimmock PW, Jones PW, Shaughn O'Brien PM. Efficacy of vitamin B-6 in the treatment of premenstrual syndrome: systematic review. BMJ. 1999;318(7195):1375-1381.

55. Whelan AM, Jurgens TM, Naylor H. Herbs, vitamins and minerals in the treatment of premenstrual syndrome: a systematic review. Can J Clin Pharmacol. 2009;16(3):e407-e429.

56. Busse JW, Montori VM, Krasnik C, Patelis-Siotis I, Guyatt GH. Psychological intervention for premenstrual syndrome: a meta-analysis of randomized controlled trials. Psychother Psychosom. 2009; 78(1):6-15.

57. Lustyk MK, Gerrish WG, Shaver S, Keys SL. Cognitive-behavioral therapy for premenstrual syndrome and premenstrual dysphoric disorder: a systematic review. Arch Womens Ment Health. 2009;12(2):85-96.

58. Thys-Jacobs S, Starkey P, Bernstein D, Tian J. Calcium carbonate and the premenstrual syndrome: effects on premenstrual and menstrual symptoms. Premenstrual Syndrome Study Group. Am J Obstet Gynecol. 1998;179(2):444-452.
International Journal of Women's Health

\section{Publish your work in this journal}

The International Journal of Women's Health is an international, peerreviewed open-access journal publishing original research, reports, editorials, reviews and commentaries on all aspects of women's healthcare including gynecology, obstetrics, and breast cancer. The manuscript management system is completely online and includes

\section{Dovepress}

a very quick and fair peer-review system, which is all easy to use. Visit http://www.dovepress.com/testimonials.php to read real quotes from published authors. 